\title{
Operative blood loss and use of blood products after full robotic and conventional low anterior resection with total mesorectal excision for treatment of rectal cancer
}

\author{
Roberto Biffi · Fabrizio Luca • Simonetta Pozzi • \\ Sabine Cenciarelli $\cdot$ Manuela Valvo $\cdot$ Angelica Sonzogni $\cdot$ \\ Davide Radice $\cdot$ Tiago Leal Ghezzi
}

Received: 25 August 2010/ Accepted: 3 November 2010/Published online: 16 December 2010

(C) The Author(s) 2010. This article is published with open access at Springerlink.com

\begin{abstract}
To date, no studies have investigated the estimated blood loss (EBL) after full robotic low anterior resection (R-LAR) in a case-matched model, comparing it with the conventional open approach (O-LAR). Forty-nine patients in the R-LAR and 105 in the O-LAR group were matched for age, gender, BMI (body mass index), ASA (American Society of Anesthesiology) class, tumor-nodemetastasis (TNM) classification and UICC (Union for International Cancer Control) stage, distance of the lower edge of the tumor from the anal verge, presence of comorbidities, and preoperative hemoglobin $(\mathrm{Hb})$. EBL was significantly higher in the O-LAR group $(P<0.001)$; twelve units of packed red blood cells were globally transfused in the O-LAR group, compared to one unit only in the R-LAR $(P=0.051)$. A significantly higher postoperative $\mathrm{Hb}$ drop ( 3.0 vs. $2.4 \mathrm{~g} / \mathrm{dL}, P=0.015$ ) was registered in the O-LAR patients. The length of hospital stay was much lower for the R-LAR group (8.4 vs. 12.4 days, $P<0.001)$. The number of harvested lymph nodes $(17.4$ vs. $13.5, P=0.006)$ and extent of distal margin (2.9 vs. $1.9 \mathrm{~cm}, P<0.001$ ) were significantly higher in the R-LAR group. Open surgery was confirmed as the sole variable
\end{abstract}

R. Biffi $(\bowtie) \cdot$ F. Luca · S. Pozzi · S. Cenciarelli - M. Valvo ·

T. L. Ghezzi

Division of Abdomino-Pelvic Surgery,

European Institute of Oncology, Via Ripamonti 435,

20141 Milan, Italy

e-mail: roberto.biffi@ieo.it

\section{A. Sonzogni}

Division of Pathology, European Institute of Oncology,

Milan, Italy

D. Radice

Division of Epidemiology and Biostatistics,

European Institute of Oncology, Milan, Italy significantly associated $(P<0.001)$ with blood loss (odds ratio $=4.41,95 \%$ CI 2.06-9.43). It was a confirmed prognosticator of blood loss $(P=0.006)$ when a preoperative clinical predictive model was built, using multivariate analysis (odds ratio $=3.95,95 \%$ CI $1.47-10.6$ ). In conclusion, R-LAR produced less operative blood loss and less drop in postoperative hemoglobin when compared to O-LAR. Other clinically relevant outcomes were similar or superior to O-LAR.

Keywords Full robotic low anterior resection . Low anterior resection - Estimated blood loss . Hemoglobin · Transfusion

\section{Introduction}

Precise robotic movements and fine manipulation of tissues in a close and fixed operating field make rectal cancer surgery an important application of robotic surgery, and in fact robot-assisted low-anterior resection (R-LAR) - with either total or tumor-specific mesorectal excision (TME)was reported by several authors as a technically feasible and oncologically safe procedure for treatment of rectal cancer [1-5]. As robotic views of the operating field during R-LAR procedures require a relatively bloodless field, R-LAR might be expected to lead to less operative blood loss than open conventional low anterior resection (O-LAR). This has some interest for clinicians, as it has been reported that allogenic blood transfusion might be associated with an increased risk of tumor recurrence after colorectal cancer surgery $[6,7]$. Studies of blood loss after O-LAR have had variable results, with rates of perioperative transfusions ranging from 20 to $75 \%$ [8]. To date, some studies have reported estimated blood loss (EBL) 
after R-LAR $[9,10]$, but no study has investigated this topic as a case-matched model, comparing open and robotic approaches. This study compares blood loss as measured by EBL, mean drop in hemoglobin levels with surgery, and blood product use in patients undergoing $\mathrm{O}-$ LAR or R-LAR in different periods of time at the same institution, maintaining the same guidelines for transfusion in the postoperative period. In addition, some clinically relevant data on early outcomes were investigated.

\section{Methods}

All patients undergoing R-LAR or O-LAR in this study were entered into a prospectively-managed database, along with their age, sex, diagnosis received (including pathologic stage), and data regarding preoperative chemo-radiation therapy performed, if any. Only tumors with the distal edge within $12 \mathrm{~cm}$ of the anal verge were considered for this study. Operative details included operating time, American Society of Anesthesiologists (ASA) class, body mass index (BMI), EBL, and complications, including readmission within 30 days of hospital discharge.

Standard surgical techniques-emphasizing the need for TME - were routinely applied during this study, as previously published elsewhere $[4,11]$. A da Vinci $\mathrm{S}^{\mathrm{TM}}$ surgical robot was always used for this study (Intuitive Surgical, Sunnyvale, CA). Surgical specimens were routinely dissected by experienced pathologists not aware of the surgical technique used. Pathologic examination included disease tumor-node-metastasis (TNM) stage, number of lymph nodes harvested, and longitudinal and radial margins of resection using standard techniques; in some cases, depending on the pathologist's judgement, clearing fixatives were used prior to the dissection.

Consecutive unselected patients undergoing R-LAR between January 2007 and December 2009 were matched with patients undergoing O-LAR in the same institution during a previous 3-year period-between January 2004 and December 2006-for age, gender, ASA class and comorbidity as denoted by the hospital coding system (Diagnosis Related Grouping). In the O-LAR group, only patients without a history of major laparotomy (except cholecystectomy, appendectomy, or gynecologic surgery by a lower abdomen incision) were considered for comparison with the R-LAR group. Preoperative values for hemoglobin level and the corresponding postoperative values taken routinely on the first and third day after surgery were gathered by reviewing the central laboratory computer software system, into which all laboratory results were routinely entered. In this way, the mean drop in hemoglobin levels with surgery was registered.
EBL was regularly recorded on the patient's chart at the end of the surgical procedure by the anesthesiologist and scrub nurse; drainage containers, and number of sponges and gauze pads used were carefully assessed.

The number of units of blood transfused on the day of surgery, during the first $48 \mathrm{~h}$ after surgery, and for the duration of the patient's hospital stay were determined from the central laboratory computer software system, and cross-checked with data contained in the patient's cards.

The recommended standard transfusion trigger for the institution is to give red blood packed cells to patients with a $\mathrm{Hb}$ level lower than $7 \mathrm{~g} / \mathrm{dL}$, unless the patient has a history of cardiac disease or there is active bleeding. This policy did not change during the entire 6-year period of the study, between January 2004 and December 2009.

Data on postoperative course and complications were reported on hospital cards by the surgical team. In addition, an epidemiology nurse was in charge to regularly collect microbiology data with respect to nosocomial infections (surgical site infections, pneumonias, urine, and intravascular catheters).

All complications were registered, with the exception of those considered as deviations from the normal postoperative course without the need for pharmacologic treatment or surgical, endoscopic, and radiologic interventions, according to the classification method proposed by Clavien et al. [12].

Hospital discharge was subjected to pre-defined conditions, in agreement with institutional policy, including fully resumed oral feeding, recovered intestinal function, autonomous walking, and approval of responsible physician.

\section{Statistical analysis}

Summary statistics (counts, percentages, mean, median, standard deviation, min and max) for patients' characteristics, pathologic findings and clinically relevant postoperative outcomes except blood loss were tabulated according to surgery type. Blood loss was summarized using mean, median, 5th and 95th percentiles, and boxplotted against type of surgery. Categorical variables were compared using Fisher's exact test or the chi-square test. After checking the normality assumption (KolmogorovSmirnov test), continuous variables were compared using either the Wilcoxon two-sample test or the unpaired $t$-test as appropriate. Univariate and multivariate odds ratios with 95\% confidence intervals were estimated in a logistic regression model after removing collinear predictors. All tests were considered statistically significant at $\alpha=0.05$ and two-sided. All analyses were conducted using SAS 9.2 software (Cary, NC, USA). 


\section{Results}

Forty-nine patients in the R-LAR and 105 in the O-LAR group could be fully matched for age, gender, BMI, TNM classification, and UICC (Union for International Cancer Control) stage, distance of the lower edge of the tumor from the anal verge, presence of comorbidities, and preoperative $\mathrm{Hb}$. No patients received preoperative transfusions, as $\mathrm{Hb}$ values were found normal in all patients. ASA class III patients were significantly more prevalent in the open-surgery group, whereas the percentage of patients who underwent neoadjuvant preoperative chemo-radiation therapy was significantly higher in the robotic surgery group (Table 1).
EBL was significantly higher in the O-LAR group $(P<0.001) ; 75 \%$ of R-LAR patients did not experienced any clinically significant intraoperative blood loss, compared to $41 \%$ of the O-LAR group $(P=0.001)$, as shown in Table 2 and Fig. 1. Neither intraoperative transfusions nor deaths were observed in these series (Table 3). Six patients in the O-RAR and only one in the R-LAR group received transfusions in the postoperative period $(P=0.432)$; twelve units of packed red blood cells were transfused in the O-LAR group compared to one unit in the R-LAR patients $(P=0.051)$. A significantly higher postoperative $\mathrm{Hb}$ drop (3.0 vs. $2.4 \mathrm{~g} / \mathrm{dL}, P=0.015$ ) was registered in the O-LAR patients; postoperative complication rates did not differ significantly between the matched
Table 1 Characteristics of the matched patients who underwent low anterior rectal resection by the open and robotic approaches

\begin{tabular}{|c|c|c|c|}
\hline Characteristic & Open-LAR & Robotic-LAR & $P$ value* \\
\hline Continuous variables & Mean $\pm \mathrm{SD}$ & Mean $\pm \mathrm{SD}$ & \\
\hline Age (years) & $61.6 \pm 11.7$ & $59.5 \pm 11.3$ & 0.414 \\
\hline BMI & $24.9 \pm 3.6$ & $24.9 \pm 4.0$ & 0.956 \\
\hline Distance from the anal verge $(\mathrm{cm})$ & $7.9 \pm 3.4$ & $6.9 \pm 2.6$ & 0.091 \\
\hline Preoperative $\mathrm{Hb}(\mathrm{g} / \mathrm{dL})$ & $13.5 \pm 1.5$ & $13.3 \pm 1.5$ & 0.392 \\
\hline Categorical variables & $N(\%)$ & $N(\%)$ & \\
\hline \multicolumn{4}{|l|}{ Sex } \\
\hline Female & $42(40.0)$ & $22(44.9)$ & \multirow[t]{2}{*}{0.601} \\
\hline Male & $63(60.0)$ & $27(55.1)$ & \\
\hline \multicolumn{4}{|l|}{ ASA class } \\
\hline I & $13(12.5)$ & $9(18.4)$ & \multirow{3}{*}{$<0.001$} \\
\hline II & $51(49.0)$ & 38 (77.6) & \\
\hline III & $40(38.5)$ & $2(4.1)$ & \\
\hline \multicolumn{4}{|l|}{ Tumor stage (TNM) } \\
\hline T0 & $15(14.3)$ & $10(20.8)$ & \multirow[t]{5}{*}{0.843} \\
\hline $\mathrm{T} 1$ & $9(8.6)$ & $3(6.3)$ & \\
\hline $\mathrm{T} 2$ & $31(29.5)$ & & \\
\hline $\mathrm{T} 3$ & $47(44.8)$ & $20(41.7)$ & \\
\hline $\mathrm{T} 4$ & $3(2.9)$ & $2(4.2)$ & \\
\hline \multicolumn{4}{|l|}{ Node stage (TNM) } \\
\hline No & $65(61.9)$ & $30(62.5)$ & \multirow[t]{3}{*}{0.878} \\
\hline 1 & $31(29.5)$ & $15(31.2)$ & \\
\hline 2 & $9(8.6)$ & $3(6.3)$ & \\
\hline \multicolumn{4}{|l|}{ Metastases stage (TNM) } \\
\hline M0 & $98(93.3)$ & $42(91.3)$ & \multirow[t]{2}{*}{0.659} \\
\hline 1 & $7(6.7)$ & $4(8.7)$ & \\
\hline \multicolumn{4}{|l|}{ UICC Stage } \\
\hline I & $23(21.9)$ & $12(24.5)$ & \multirow{4}{*}{0.979} \\
\hline II & $40(38.1)$ & $19(38.8)$ & \\
\hline III & $35(33.3)$ & $15(30.6)$ & \\
\hline IV & $7(6.7)$ & $3(6.1)$ & \\
\hline Neoadjuvant preop CT/RT & $55(52.4)$ & $36(73.5)$ & 0.013 \\
\hline Presence of comorbidities & $40(38.1)$ & $21(42.9)$ & 0.574 \\
\hline
\end{tabular}


Table 2 Estimated blood loss in the open and robotic groups

\begin{tabular}{lllr}
\hline Blood loss & Open-LAR & $\begin{array}{l}\text { Robotic- } \\
\text { LAR }\end{array}$ & $P$ value* \\
\hline None, $N(\%)$ & $42(41.2)$ & $36(75.0)$ & $<0.001$ \\
Mean (5th, 95th percentiles) & $146.4(0,500)$ & $83.7(0,500)$ & 0.001 \\
Median & 100 & 0 & \\
Min, max & 0,2000 & 0,1500 & \\
\hline
\end{tabular}

* Fisher's two-sided test or Wilcoxon test as appropriate

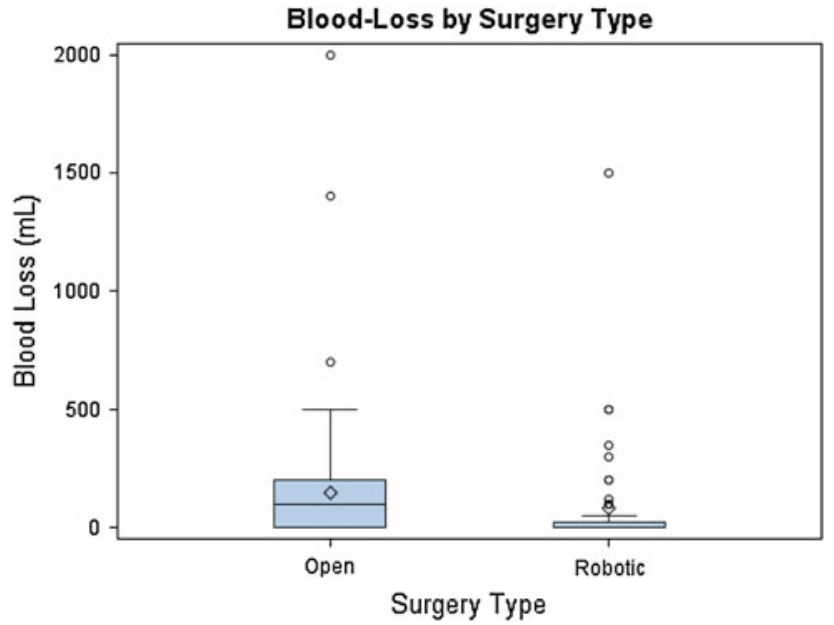

Fig. 1 Box-plots of estimated blood loss in the open and robotic groups

groups, either for infectious or non-infectious complications. No patients in the R-LAR group experienced a conversion to laparotomy; two patients needed another operation, but bleeding was not the cause. Finally, the length of hospital stay was much lower for the R-LAR group (8.4 vs. 12.4 days, $P<0.001$ ). With respect to relevant pathologic findings, radial circumferential margins did not differ significantly between the groups (about $100 \%$ of free margin for both), whereas number of harvested lymphnodes (17.4 vs. $13.5, P=0.006)$ and extent of distal margin ( 2.9 vs. $1.9 \mathrm{~cm}, P<0.001)$ were significantly more favorable in the robotic group (Table 4).

Univariate analysis of blood-loss risk estimates was performed, taking into consideration a number of possible variables (Table 5). Only open surgery was confirmed to be significantly associated $(P<0.001)$ with blood loss during the hospital stay (odds ratio $=4.41,95 \%$ CI $2.06-9.43$, compared with referenced robotic surgery). Open surgery was again confirmed as the only prognosticator of blood loss $(P=0.006)$ when a preoperative clinical predictive model was built, using a multivariate analysis of blood-loss risk estimate (odds ratio $=3.95,95 \%$ CI $1.47-10.6$, compared with referenced robotic surgery) (Table 6).

\section{Discussion}

Previous studies have already supported the feasibility and oncologic safety of robotic LAR, although their results were limited by the small number of cases representing the early phase of the learning curve [13]. Since the first reports of robot-assisted rectal cancer surgery, the advantages of the robotic approach were focused on better early postoperative outcomes compared with conventional open analogue procedures, including earlier recovery, less postoperative pain due to smaller incisions, and a shorter postoperative hospital stay [14]. Blood loss has not been investigated in depth until now, in spite of immunosuppression, an untoward effect of allogenic transfusion, which has been postulated to result in decreased tumor surveillance and detrimental outcome. In 1982, Burrows and Tartter first linked perioperative allogenic blood
Table 3 Clinically relevant outcomes

* Two-sample two-sided Wilcoxon test, unpaired $t$ test, chi-square or two-sided Fisher's exact test as appropriate

\begin{tabular}{llll}
\hline Outcome & Open-LAR & Robotic-LAR & $P$ value* \\
\hline Intraoperative transfusions & 0 & 0 & - \\
Death & 0 & 0 & - \\
Postoperative transfusions & & & 0.432 \\
Patients, $N(\%)$ & $6(5.7)$ & $1(2.0)$ & 0.051 \\
$\quad$ Units, $N$ & 12 & 1 & 0.189 \\
Surgical complications (30th postoperative day) & & & \\
Infectious & $15(14.3)$ & $8(16.3)$ & $10(20.4)$ \\
$\quad$ Non-infectious & $11(10.5)$ & 0 & 0.371 \\
$\quad$ Both & $5(4.5)$ & $18(36.7)$ & 0.100 \\
$\quad$ Overall & $31(29.5)$ & $2(4.1)$ & $<0.001$ \\
Reinterventions (30th postoperative day) & 0 & $8.4 \pm 9.3(7.0)$ & 0.124 \\
Length of hospital stay (days) mean \pm SD (median) & $12.4 \pm 3.2(12.0)$ & 0.015 \\
Post-operative Hb (g/dL) mean \pm SD (median) & $10.6 \pm 1.6(10.8)$ & $11.0 \pm 1.4(10.8)$ \\
Hb drop (g/dL) mean \pm SD (median) & $3.0 \pm 1.4(2.9)$ & $2.4 \pm 1.6(2.0)$ & \\
\hline
\end{tabular}


Table 4 Pathological findings

* Two-sample two-sided

Wilcoxon test, unpaired $t$ test, chi-square or two-sided Fisher's exact test as appropriate

\begin{tabular}{lllr}
\hline Parameter & Open-LAR & Robotic-LAR & $P$ value* $^{*}$ \\
\hline Radial margin $(\mathrm{cm}), N(\%)$ & & & \\
Negative & $103(98.1)$ & $49(100)$ & 1.000 \\
Positive & $2(1.9)$ & 0 & \\
Harvested lymphnodes, mean \pm SD & $13.5 \pm 6.7$ & $17.4 \pm 8.7$ & 0.006 \\
Distal margin $(\mathrm{cm})$, mean $\pm \mathrm{SD}($ median$)$ & $1.9 \pm 1.2(1.8)$ & $2.9 \pm 1.6(2.6)$ & $<0.001$ \\
\hline
\end{tabular}

transfusion to the prognosis of colorectal malignancy [15]. More recently (2006), a Cochrane Collaboration Review [16] confirmed in an updated meta-analysis the hypothesis that perioperative blood transfusions have a detrimental effect on the recurrence of curable colorectal cancers; the authors concluded that carefully restricted indications for allogenic blood transfusion are necessary in this clinical setting, although a causal relationship cannot be claimed, due to the heterogeneity detected and the not yet completely defined impact of surgical technique [17].

To date, there is no uniform consensus on the relative blood loss when patients undergo low anterior resection for cancer using an open or a robotic approach, and that is true also for laparoscopic low anterior resection. While some studies found that EBL during minimally invasive colorectal resections was significantly lower than during analogue open procedures [18-21], others found the loss to be comparable [22, 23]. A possible reason could be the fact that most of these studies used EBL as the sole measure of blood loss during surgery, a parameter previously reported to be an inconsistent estimate of real blood loss [24, 25]. We used two additional measures to precisely define the blood loss related to surgery: postoperative hemoglobin level drop and overall use of blood products. Hemoglobin drop was much less in the robotic group, thus confirming a significant superiority of robot-assisted LAR in this clinical setting, whereas overall use of blood products showed a trend in favor of the R-LAR patients (12 vs. 1 units of packed red blood cells, $P=0.051$ ). In both univariate and multivariate analyses, conventional open surgery was confirmed as the sole variable significantly associated with blood loss; moreover, it was confirmed as a prognosticator of blood loss when a preoperative clinical predictive model was built.

Interestingly, oncology outcomes were also in favor of the robotic group, as witnessed by a higher number of harvested lymph nodes and a higher extent of free distal margin in the surgical specimens, thus confirming previous observations of our and other groups [13]. These results have been obtained while maintaining a comparable rate of surgical peroperative complications and a much lower hospital stay in the R-LAR group.

There are several limitations of this study that deserve some mentions. First, this is not a randomized trial, and therefore it could suffer from the typical limitations of observational-descriptive studies. Nevertheless, this is the first study specifically addressing the topic of blood loss and use of blood products in robotic low anterior resection, by means of a comparison between two quite large series of case-matched patients undergoing the same oncology procedure (low anterior resection) by the same surgical team, using a conventional open and a full robotic approach in the same institution and in a consecutive period of 6 years (three per group). During this study period, practice of care, perioperative management, and, in particular, transfusional policies did not change in our institution.

Another point to be noted is matching, since a potentially important difference between the groups was the higher prevalence of ASA class 3 in the open surgery one. This could reflect possible changes in the attitude and judging of attending anesthesiologists, to whom patients' ASA classification is routinely given, as the anesthesiology team differed during the study periods, unlike the surgical one. However, our multivariate analysis is adjusted for all patients and tumor characteristics of prognostic relevance, and it excluded ASA class as a variable possibly associated with blood loss.

The higher prevalence in the robotic arm of patients who underwent preoperative neoadjuvant treatment $(73.5 \%$ vs. $52,4 \%, P=0.013)$ is worth of further comment. Use of preoperative neoadjuvant chemo-radiation therapy became a standard option in our institution for locally advanced disease, preoperatively staged as any $\mathrm{T}, \mathrm{N}$ positive or $\geq \mathrm{T} 3$, any $\mathrm{N}$, and this explains the higher prevalence of these cases in the second group (R-LAR), treated since 2007. A large previous trial, using a conventional open approach, reported that patients randomly assigned to preoperative radiation therapy lost more blood than those assigned to surgery alone (median blood loss 1,000 vs. $900 \mathrm{~mL} ; P<0.001$ ) [26]. Our data do not confirm these results: firstly, no differences were detected between preoperative chemo-radiation and immediate surgery groups in terms of EBL; moreover, median EBL for open surgery was only $100 \mathrm{~mL}$, and zero $\mathrm{mL}$ for the robotic group. These findings probably reflect a significant and general improvement in surgical techniques, since these reference surgical data come from a national study concluded in the late 1990s; moreover, they underline the superiority of the robotic technique applied to LAR also in "difficult" 
Table 5 Univariate blood-loss risk estimates

\begin{tabular}{|c|c|c|}
\hline Risk factor & Odds ratio $(95 \% \mathrm{CI})$ & $P$ value* \\
\hline \multicolumn{3}{|l|}{ Surgery } \\
\hline Robotic & Reference & \\
\hline Open & $4.41(2.06,9.43)$ & $<0.001$ \\
\hline \multicolumn{3}{|l|}{ Sex } \\
\hline Male & Reference & \\
\hline Female & $0.54(0.28,1.04)$ & 0.067 \\
\hline \multicolumn{3}{|c|}{ Age (years) } \\
\hline$\leq 62^{\mathrm{a}}$ & Reference & \\
\hline$>62$ & $0.74(0.39,1.41)$ & 0.360 \\
\hline \multicolumn{3}{|l|}{ BMI } \\
\hline$\leq 25^{\mathrm{a}}$ & Reference & \\
\hline$>25$ & $1.65(0.87,3.15)$ & 0.125 \\
\hline \multicolumn{3}{|c|}{ Distance anal verge $(\mathrm{cm})$} \\
\hline$\leq 7^{\mathrm{a}}$ & Reference & \\
\hline$>7$ & $0.64(0.34,1.23)$ & 0.183 \\
\hline \multicolumn{3}{|c|}{ Surgery time (min) } \\
\hline$\leq 223^{\mathrm{a}}$ & Reference & \\
\hline$>223$ & $0.78(0.40,1.50)$ & 0.448 \\
\hline \multicolumn{3}{|c|}{ Lymph nodes } \\
\hline$\leq 14^{\mathrm{a}}$ & Reference & \\
\hline$>14$ & $0.54(0.29,1.05)$ & 0.068 \\
\hline \multicolumn{3}{|l|}{ Ostomy } \\
\hline No & Reference & \\
\hline Yes & $0.61(0.32,1.16)$ & 0.132 \\
\hline \multicolumn{3}{|l|}{ ASA } \\
\hline I & Reference & \\
\hline II & $1.46(0.56,3.83)$ & 0.443 \\
\hline III & $2.52(0.86,7.39)$ & 0.093 \\
\hline \multicolumn{3}{|c|}{ Neoadjuvant CT/RT } \\
\hline No & Reference & \\
\hline Yes & $0.90(0.47,1.73)$ & 0.762 \\
\hline \multicolumn{3}{|c|}{ UICC Stage } \\
\hline I & Reference & \\
\hline II & $0.63(0.27,1.49)$ & 0.291 \\
\hline III & $0.47(0.19 .1 .13)$ & 0.092 \\
\hline IV & $0.70(0.17,2.88)$ & 0.621 \\
\hline \multicolumn{3}{|l|}{ TNM } \\
\hline $\mathrm{T} 0-\mathrm{T} 1$ & Reference & \\
\hline $\mathrm{T} 2$ & $1.33(0.50,3.58)$ & 0.568 \\
\hline $\mathrm{T} 3-\mathrm{T} 4$ & $0.60(0.24,1.52)$ & 0.280 \\
\hline \multicolumn{3}{|c|}{ Comorbidities } \\
\hline No & Reference & \\
\hline Yes & $0.58(0.30,1.12)$ & 0.106 \\
\hline
\end{tabular}

${ }^{a}$ Median value

* Two-sample two-sided Wilcoxon test, unpaired $t$ test, chi-square or two-sided Fisher's exact test as appropriate
Table 6 Multivariate blood-loss risk estimates-pre-operative clinical predictive model

\begin{tabular}{|c|c|c|}
\hline Risk factor & Odds ratio $(95 \% \mathrm{CI})$ & $P$ value \\
\hline \multicolumn{3}{|l|}{ Surgery } \\
\hline Robotic & Reference & \\
\hline Open & $3.95(1.47,10.6)$ & 0.006 \\
\hline \multicolumn{3}{|l|}{ Sex } \\
\hline Male & Reference & \\
\hline Female & $0.57(0.25,1.30)$ & 0.179 \\
\hline \multicolumn{3}{|c|}{ Age (years) } \\
\hline$\leq 62$ & Reference & \\
\hline$>62$ & $0.55(0.25,1.23)$ & 0.147 \\
\hline \multicolumn{3}{|l|}{ BMI } \\
\hline$\leq 25^{\mathrm{a}}$ & Reference & \\
\hline$>25$ & $1.29(0.60,2.79)$ & 0.513 \\
\hline \multicolumn{3}{|c|}{ Distance from anal verge $(\mathrm{cm})$} \\
\hline$\leq 7^{\mathrm{a}}$ & Reference & \\
\hline$>7$ & $0.50(0.19,1.26)$ & 0.136 \\
\hline \multicolumn{3}{|c|}{ Surgery time $(\mathrm{min})$} \\
\hline$\leq 223^{\mathrm{a}}$ & Reference & \\
\hline$>223$ & $1.18(0.48,2.93)$ & 0.712 \\
\hline \multicolumn{3}{|l|}{ ASA } \\
\hline I & Reference & \\
\hline II & $1.45(0.47,4.42)$ & 0.518 \\
\hline III & $2.02(0.55,7.46)$ & 0.292 \\
\hline \multicolumn{3}{|c|}{ Neoadjuvant CT/RT } \\
\hline No & Reference & \\
\hline Yes & $0.78(0.32,2.27)$ & 0.596 \\
\hline \multicolumn{3}{|c|}{ UICC Stage } \\
\hline I & Reference & \\
\hline II & $0.56(0.20,1.57)$ & 0.273 \\
\hline III & $0.42(0.14 .1 .26)$ & 0.120 \\
\hline IV & $0.67(0.14,3.20)$ & 0.618 \\
\hline
\end{tabular}

a Median value

patients, such as those who underwent chemo-radiation neoadjuvant treatment. With respect to this issue, it is noteworthy to point out that we always applied-in both groups-one or more sheets of regenerated oxidized cellulose $\left(\right.$ Tabotamp $^{\circledR}$ or Tabotamp Fibrillar ${ }^{\circledR}$, Johnson \& Johnson, Pratica di Mare, Rome, Italy) in case of residual bleeding after mesorectal excision, usually coming from small sacral and coccygeal interrupted venules. This is a 
fairly common finding in pretreated rectal cancer patients, where the presacral Waldayer's fascia is frequently involved in a thick, fibrous post-radiation tissue, and sacrococcygeal venules cannot be easily identified.

In conclusion, this study specifically evaluated whether robotic LAR reduces estimated intraoperative blood loss, postoperative $\mathrm{Hb}$ drop, and use of blood products when compared with carefully matched open LAR cases. Robotic LAR was found to lead to significantly less operative blood loss and less postoperative $\mathrm{Hb}$ drop, together with much lower use of blood products $(P=0.051)$ in these patients. Other clinically relevant outcomes-like length of hospital stay and pathologic findings-were found similar or superior to open LAR.

Open Access This article is distributed under the terms of the Creative Commons Attribution Noncommercial License which permits any noncommercial use, distribution, and reproduction in any medium, provided the original author(s) and source are credited.

\section{References}

1. Hance J, Rockall T, Darzi A (2004) Robotics in colorectal surgery. Dig Surg 21:339-343

2. Hellan M, Anderson C, Ellenhorn JD, Paz B, Pigazzi A (2007) Short-term outcomes after robotic-assisted total mesorectal excision for rectal cancer. Ann Surg Oncol 14:3168-3173 Epub 2007 Sep 1

3. Spinoglio G, Summa M, Priora F, Quarati R, Testa S (2008) Robotic colorectal surgery: first 50 cases experience. Dis Colon Rectum 51:1627-1632 Epub 2008 May 17

4. Luca F, Cenciarelli S, Valvo M, Pozzi S, Lo Faso FL, Ravizza D, Zampino G, Sonzogni A, Biffi R (2009) Full robotic left colon and rectal cancer resection: technique and early outcome. Ann Surg Oncol 16:1274-1278 Epub 2009 Feb 26

5. Baik SH, Ko YT, Kang CM, Lee WJ, Kim NK, Sohn SK, Chi HS, Cho CH (2008) Robotic tumor-specific mesorectal excision of rectal cancer: short-term outcome of a pilot randomized trial. Surg Endosc 22:1601-1608 Epub 2008 Feb 13

6. Tang R, Wang JY, Chien CR, Chen JS, Lin SE, Fan HA (1993) The association between perioperative blood transfusion and survival of patients with colorectal cancer. Cancer 72:341-348

7. Edna TH, Bjerkeset T (1998) Perioperative blood transfusions reduce long-term survival following surgery for colorectal cancer. Dis Colon Rectum 41:451-459

8. De Canniere I, Rosiere A, Michel LA (1998) Synchronous abdominoperineal resection without transfusion. $\mathrm{Br}$ J Surg 80:1194-1195

9. D'Annibale A, Morpurgo E, Fiscon V, Trevisan P, Sovernigo G, Orsini C, Guidolin D (2004) Robotic and laparoscopic surgery for treatment of colorectal diseases. Dis Colon Rectum 47:2162-2168

10. Hellan M, Stein H, Pigazzi A (2009) Totally robotic low anterior resection with total mesorectal excision and splenic flexure mobilization. Surg Endosc 23:447-451
11. Chiappa A, Biffi R, Bertani E, Zbar AP, Pace U, Crotti C, Biella F, Viale G, Orecchia R, Pruneri G, Poldi D, Andreoni B (2006) Surgical outcomes after total mesorectal excision for rectal cancer. J Surg Oncol 94: 182-193 (discussion 181)

12. Clavien PA, Barkun J, de Oliveira ML, Vauthey JN, Dindo D, Schulick RD, de Santibañes E, Pekolj J, Slankamenac K, Bassi C, Graf R, Vonlanthen R, Padbury R, Cameron JL, Makuuchi M (2009) The Clavien-Dindo classification of surgical complications: five-year experience. Ann Surg 250:187-196

13. Pigazzi A, Luca F, Patriti A, Valvo M, Ceccarelli G, Casciola L, Biffi R, Garcia-Aguilar J, Baek JH (2010) Multicentric study on robotic tumor-specific mesorectal excision for the treatment of rectal cancer. Ann Surg Oncol 17:1614-1620 Epub 2010 Jan 20

14. Ziogas D, Roukos D (2008) Robotic surgery for rectal cancer: may it improve also survival? Surg Endosc 22:1405-1406

15. Burrows L, Tartter P (1982) Effect of blood transfusion on colonic malignancy rate. Lancet 2:662

16. Amato A, Pescatori M (2006) Perioperative blood transfusions for the recurrence of colorectal cancer. Cochrane Database Syst Rev Jan 5(1):CD005033

17. Jagoditsch M, Pozgainer P, Klinger A, Tschmelitsch J (2006) Impact of blood transfusions on recurrence and survival after rectal cancer surgery. Dis Colon Rectum 49:1116-1130

18. Franklin ME Jr, Rosenthal D, Abrego-Medina D, Dorman JP, Glass JL, Norem R, Diaz A (1996) Prospective comparison of open vs. laparoscopic colon surgery for carcinoma. Five-year results. Dis Colon Rectum 39(10):S35-S46

19. Senagore AJ, Luchtefeld MA, Mackeigan JM, Mazier WP (1993) Open colectomy versus laparoscopic colectomy: are there differences? Am Surg 59:549-554

20. Kakisako K, Sato K, Adachi Y, Shiraishi N, Miyahara M, Kitano S (2000) Laparoscopic colectomy for Dukes A colon cancer. Surg Laparosc Endosc Oercutan Tech 10:66-70

21. Kiran RP, Delaney CP, Senagore AJ, Millward BL, Fazio VW (2004) Operative blood loss and use of blood products after laparoscopic and conventional open colorectal operations. Arch Surg 139:39-42

22. Marubashi S, Yano H, Monden T, Hata T, Takahashi H, Fujita S, Kanoh T, Iwazawa T, Matsui S, Nakano Y, Tateishi H, Kinuta M, Takiguchi S, Okamura J (2000) The usefulness, indications, and complications of laparoscopy-assisted colectomy in comparison with those of open colectomy for colorectal carcinoma. Surg Today 30:491-496

23. Joo JS, Amarnath L, Wexner SD (1998) Is laparoscopic resection of colorectal polyps beneficial? Surg Endosc 12:1341-1344

24. Meiser A, Casagranda O, Skipka G, Laubenthal H (2001) Quantification of blood loss: how precise is visual estimation and what does its accuracy depend on? Anaesthesist 50:13-20

25. Chang SS, Smith JA Jr, Wells N, Peterson M, Kovach B, Cookson MS (2001) Estimated blood loss and transfusion requirements of radical cystectomy. J Urol 166:2151-2154

26. Kapiteijn E, Marijnen CA, Nagtegaal ID, Putter H, Steup WH, Wiggers T, Rutten HJ, Pahlman L, Glimelius B, van Krieken JH, Leer JW, van de Velde CJ (2001) Dutch colorectal cancer group. Preoperative radiotherapy combined with total mesorectal excision for resectable rectal cancer. N Engl J Med 345:638-646 